\title{
Hot Topic: Black Spot Defect in Cheddar Cheese Linked to Intramammary Teat Sealant
}

\author{
A. M. Lay, ${ }^{\star}$ K. M. Kolpin, $†$ D. A. Sommer, $\ddagger$ and S. A. Rankin $\S^{1}$ \\ ${ }^{*}$ Chr. Hansen Inc., Milwaukee, WI 53214 \\ †Department of Food Science and Technology, Oregon State University, Corvallis 97331 \\ $\ddagger$ Center for Dairy Research, and \\ $\S$ Department of Food Science, University of Wisconsin, Madison 53706
}

\begin{abstract}
The objective of this work was to characterize a novel appearance defect found in Cheddar cheese, heretofore referred to as black spot defect (BSD), and to determine an etiology. Uniformly distributed throughout the cheese mass, BSD appears as small spherical black spots from 0.20 to $4.7 \mathrm{~mm}$ in diameter and at an average frequency of about 2 spots per $\mathrm{kg}$ of cheese. To date, BSD has only been found in aged Cheddar cheese. Selected elemental analysis found the BSD region in cheese to have average concentrations of the element bismuth of approximately $400 \mu \mathrm{g} / \mathrm{g}$, representing an approximately 2,500-fold increase over native levels of bismuth in cheese. Transmission electron microscopy analysis of the BSD region revealed amorphous solid structures and one-dimensional hair-like structures, neither of which was present in non-BSD regions. Such amorphous "nanorod" structures can be formed by the crystallization of bismuth III sulfide and are proposed to be a source of black discoloration. We hypothesize that localized bismuth salts entrained within the cheese curd react with hydrogen sulfide generated during aging to generate bismuth III sulfide. We further propose that the presence of localized bismuth salt precursor results from residual levels of a commercial intramammary teat sealant containing bismuth subnitrate that becomes unintentionally entrained within the cheese milk.
\end{abstract}

Key words: cheese, black spot, Cheddar, teat sealant

A recently discovered visual defect in cheese has caused some concern within the cheese manufacturing industry. Although not apparent until some degree of cheese aging has transpired, this defect, heretofore referred to as black spot defect (BSD), can result in a dramatic reduction in the value of affected cheeses.

Received May 24, 2007.

Accepted July 25, 2007.

${ }^{1}$ Corresponding author: sarankin@wisc.edu
The Dairy Grading Branch of the USDA Agricultural Marketing Services has deemed cheese with BSD as follows, "No U.S. Grade Assigned Due to Foreign Material," making the product ineligible for either USDA grade certification or purchase under a government procurement program. Black spot defect has not been observed in cheese milk or in younger cheeses, whereas aged Cheddar cheese appears to be most susceptible. Although this work does not include specific studies to suggest a time of onset for BSD, based on the history of dozens of contributed samples received, we speculate that it takes several months for BSD to become manifest in a typical Cheddar product under a conventional aging regimen. Because cheese manufacturers are cautious about revealing the extent to which their cheese stocks are affected with BSD, there are no survey data to characterize the extent of this defect or its economic impact. Some anecdotal reports have suggested that BSD might arise from the presence of residual amounts of an intramammary test sealant (ITS; Orbeseal, Pfizer Inc., New York, NY) containing $65 \%$ bismuth subnitrate (bismuth hydroxide nitrate oxide; CAS No. 1304-85-4) in a mineral oil base. Administered during the drycow period, this commercial ITS product is used as an effective measure in the prevention of new intramammary infections (Woolford et al., 1998; McNally and Morgan, 2001). In some instances, the ITS may not be entirely removed from the udder and may be subsequently released into the milk stream as mineral oil droplets containing the proposed reactant, bismuth subnitrate.

Understandably, there is a paucity of information about BSD in the literature. To that end, twelve 18.2$\mathrm{kg}$ blocks of BSD-affected Cheddar cheese from the Midwest, West, and East regions of the United States were received from commercial cheese plants for further analysis. These cheese samples had average fat, protein, ash, and moisture contents within typical ranges (fat: $32.8 \mathrm{~g} / 100 \mathrm{~g}$, protein: $23.9 \mathrm{~g} / 100 \mathrm{~g}$, ash: $3.84 \mathrm{~g} /$ $100 \mathrm{~g}$, and moisture: $37.7 \mathrm{~g} / 100 \mathrm{~g}$ ) suggesting that the cheeses were of typical composition for natural Cheddar 


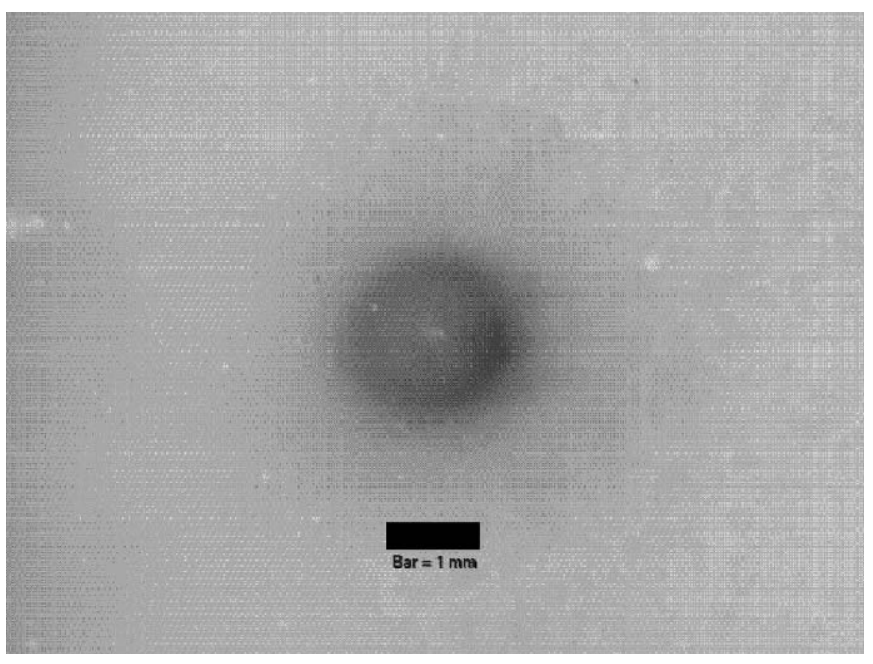

Figure 1. Image of black spot defect in aged $(>9 \mathrm{mo})$ colored Cheddar showing a characteristic "halo" around the center. Small white flecks are probable calcium lactate crystals. Color image is available online at http://jds.fass.org/content/vol90/issue11/.

(Kosikowski, 1978). Cheeses ranged in age from 4 to 8 mo at the time of receipt.

The frequency of occurrence of BSD was determined by cutting cheeses into approximately 1 -mm-wide slices using a commercial slicer and visually counting the presence of BSD spots, being cautious not to recount spots that occurred in more than one slice; calipers were used to measure the diameter of each spot. A representative image of BSD in annatto-colored Cheddar is presented in Figure 1.

The following observations are included for general consideration and as an aid in identifying this defect in other cheeses. Black spot defect spots were found equally distributed throughout each of the blocks examined with no prevalence toward accumulation at a cut surface, center, or side of the block. Black spot defect was not susceptible to light or exposure to oxygen and, once formed, did not show any fading or diffusion over time ( $>18$ mo). There was no noticeable tactile character associated with the presence of BSD spots. The spots were spherical in shape, and ranged in diameter from 0.20 to $4.7 \mathrm{~mm}$ and average $0.58 \mathrm{~mm}$ in diameter $(\mathrm{n}=$ 132). The spots ranged from a light gray to black in hue. In some cases, the larger spots had a halo-like appearance (Figure 1). Frequency of the black spots ranged from $<0.5$ to 7.3 spots per $\mathrm{kg}$ of cheese with an average frequency of 2.1 spots per $\mathrm{kg}$. The BSD region did not dissolve in solvents ranging in polarity from water to hexane, suggesting the presence of an inorganic, insoluble salt.

Inductively coupled plasma-mass spectroscopy was used to determine the presence of specific elements
Table 1. Concentrations ( $\mu \mathrm{g} / \mathrm{kg}$ ) of metal elements found in excised black spot defect (BSD) regions relative to unaffected areas of cheese ${ }^{1}$

\begin{tabular}{lrr}
\hline Element & BSD region & Non-BSD region \\
\hline Bismuth & $390,000(110,000)$ & $150(23)$ \\
Chromium & 610 & 23 \\
Copper & 790 & 390 \\
Iron & 8,600 & 2,400 \\
Nickel & 200 & 170 \\
\hline
\end{tabular}

${ }^{1}$ Values in parentheses represent 1 standard deviation $(n=4)$.

within the BSD-affected cheeses. Four black spots, 1 each from 4 manufacturers, were tested with inductively coupled plasma-mass spectroscopy (method 993.14, AOAC, 2005). In the excised BSD regions, there were modest increases in the concentrations of elements associated with milk-conveying materials: chromium, copper, iron, and nickel. However, concentrations of bismuth in the BSD regions were several orders of magnitude greater than in non-BSD regions (Table 1) suggesting that a bismuth-containing compound was a probable causative agent of BSD.

Transmission electron microscopy (TEM) was used to view both BSD and unaffected regions of cheese. Black spots for analysis were scraped $(\sim 200 \mathrm{mg})$ from cheese samples and deposited into small glass test tubes. Approximately $100 \mu \mathrm{L}$ of double distilled water was added to the samples and the mixture was pulverized into a suspension with a glass rod. Approximately $5-\mu \mathrm{L}$ aliquots of suspended sample were deposited onto coated 300-mesh copper TEM grids (Pioloform, Structure Probe Inc., West Chester, PA). Excess water was wicked away with filter paper and the remaining sample was dried to the surface of the grid at room temperature. In some cases, a TEM-negative stain (Nano-W, Nanoprobes Inc., Yaphank, NY) was applied to the dried sample to enhance contrast and visibility. Specimens were observed with an electron microscope (CM120, Philips, Koninklijke Philips, Eindhoven, the Netherlands) and images were collected with a digital camera (SIS MegaView3, Surface Imaging Systems, Herzogenrath, Germany) with measurements taken with the accompanying analysis software calibrated with reference samples of known lengths.

The TEM images showed numerous hair-like rods ranging from 37 to $350 \mathrm{~nm}$ in diameter $(\mathrm{n}=20)$ and several hundred nanometers in length. A representative TEM image is presented in Figure 2. No such structures were found in any non-BSD cheese region. Reactions involving bismuth III sulfide forming hair-like structures, termed nanorods, have been reported in the context of semiconductor technologies (Zhang et al., 2001). Certain salts of bismuth and hydrogen sulfide have long been recognized as reactants to create bis- 


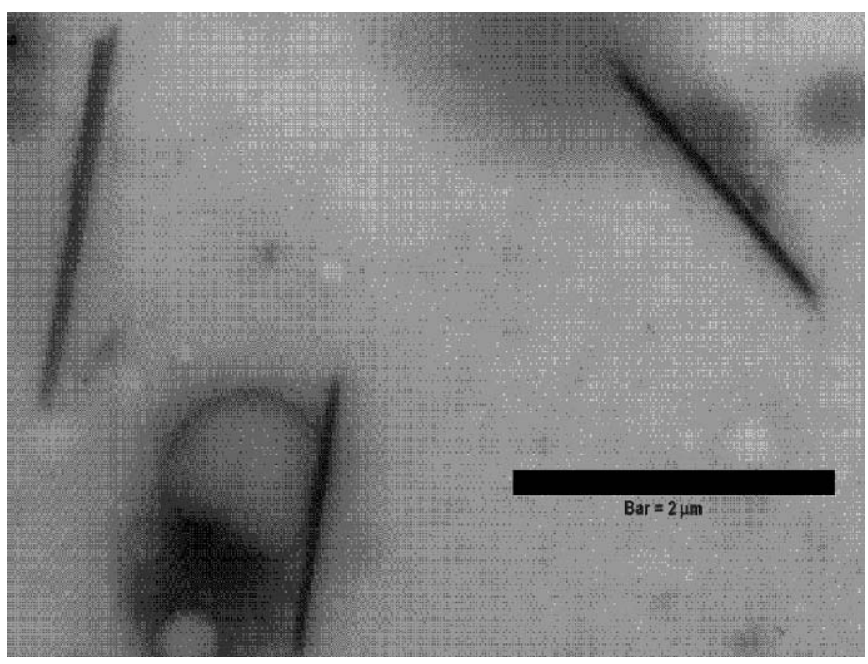

Figure 2. A representative image of typical hair-like "nanorod" structures found in black spot defect region of Cheddar cheese.

muth III sulfide, a black, crystalline compound (Heslop and Robinson, 1967) via the following reaction: $2 \mathrm{Bi}^{3+}+$ $3 \mathrm{H}_{2} \mathrm{~S} \rightarrow \mathrm{Bi}_{2} \mathrm{~S}_{3}+3 \mathrm{H}_{2}$.

We hypothesize that $\mathrm{BSD}$ results from the reaction of bismuth subnitrate-containing ITS residual with hydrogen sulfide produced during the cheese aging process (Dimosa et al., 1996; Seefeldt and Weimer, 2000). To that end, a series of experiments was conducted to evaluate this possible causative route for BSD development. An initial experiment considered whether bismuth subnitrate (a microcrystalline white powder) entrained in a cheese matrix could be induced to turn black in the presence of volatiles from aged cheese. A 0.56 -g plug was removed from young ( $<2$ mo old $)$ Cheddar cheeses and mixed with bismuth subnitrate ( $15 \% \mathrm{wt} / \mathrm{wt}$, SigmaAldrich Inc., Milwaukee, WI) with a mortar and pestle. The bismuth subnitrate/cheese mixture was replaced into the cheese and then held in a desiccator containing $1 \mathrm{~kg}$ of shredded, aged Cheddar cheese ( $\sim 9$ mo old) recognized as having a "sulfide" aroma as determined by expert cheese graders from the University of Wisconsin-Madison Center for Dairy Research. The desiccator was placed in a $10^{\circ} \mathrm{C}$ cooler and observed every $48 \mathrm{~h}$. After 2 wk, the plug containing bismuth subnitrate had turned black, with no such color development in the untreated regions of the cheese or in control regions without added bismuth subnitrate.

To test whether hydrogen sulfide may be a participating reactant from the cheese volatile profile, a similar approach was used wherein $\sim 1$-cm-diameter plugs were cut from 2.5-mm-thick young $(<2$ mo old $)$ Cheddar cheese slices. Each plug was mixed with either the intact ITS or bismuth subnitrate (15\% wt/wt); a plug without added ITS or bismuth subnitrate served as the con-

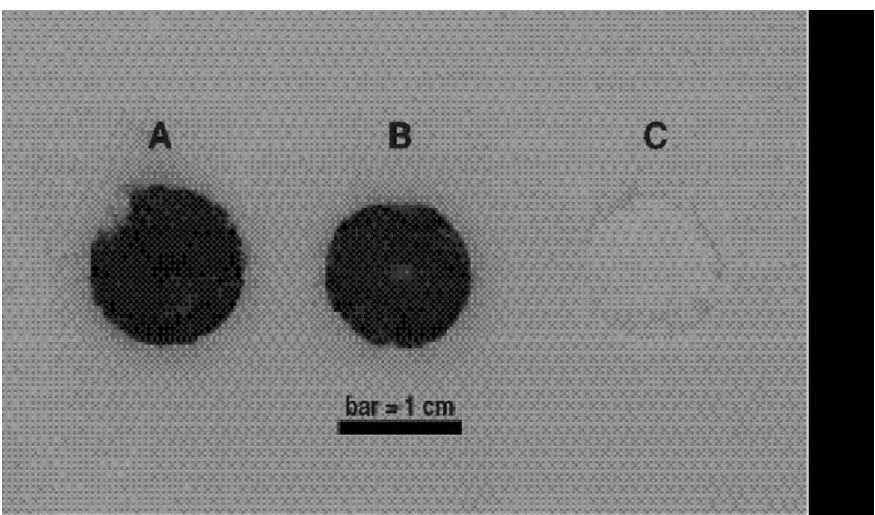

Figure 3. Cheddar cheese plugs containing 15\% (wt/wt) bismuth subnitrate (A) or intact intramammary teat sealant (B) after exposure to hydrogen sulfide gas for $10 \mathrm{~min}$. Plug $\mathrm{C}$ contained no additives. Color image is available online at http://jds.fass.org/content/vol90/ issue $11 /$.

trol (Figure 3). Each slice ( $n=3)$ was placed in a desiccator with a septum and subjected to varying levels of hydrogen sulfide gas $(0.0004,0.001$, and $0.002 \mathrm{~mol}$; Sigma-Aldrich Inc.) drawn from a lecture bottle discharge at ambient temperature and pressure and introduced into the desiccator with a gastight syringe (Hamilton, Reno, NV). The levels of hydrogen sulfide gas were reflective of the potential molar concentration of its amino acid precursors in cheese. Each sample was kept in a desiccator with hydrogen sulfide gas for 10 min, removed from the desiccator, and visually examined for the development of black discoloration.

Regardless of hydrogen sulfide level, each plug containing either bismuth subnitrate or intact ITS rapidly developed as demonstrated by the color change of the plugs from white to black upon introduction of the hydrogen sulfide. No changes were observed in the control plugs (Figure 3). The TEM images of the cheese plugs created with hydrogen sulfide and either bismuth subnitrate or ITS demonstrated the presence of both amorphous and nanorod structures similar to the commercial BSD samples.

This work creates a preliminary link between a bismuth-containing ITS and the appearance defect BSD in cheese. In short, we propose that, if residual ITS residues are entrained within the cheese curd and sufficient aging occurs to allow the liberation of hydrogen sulfide, a replacement reaction will yield bismuth III sulfide with the resulting characteristic black/gray discoloration (Cotton and Wilkinson, 1962). Although most bismuth-containing compounds are generally not associated with significant toxicity (Bierer, 1990), the appearance of BSD may result in a substantial reduction in the economic value of the cheese. Practices brought to our knowledge to reduce the possibility of BSD devel- 
opment in cheese include thorough employee training on the proper initial administration and final removal of ITS from the udder as well as the use of raw milk clarification technologies designed to physically remove the relatively dense ITS from cheese milk. Approaches to limit the formation of hydrogen sulfide may be invalid given the importance of this volatile compound to cheese aroma chemistry. The only cheese type we have observed with BSD is aged Cheddar; however, any cheese with the potential to produce hydrogen sulfide may be susceptible. While additional work is underway, this paper is intended to provide the industry with an awareness and preliminary understanding of BSD in cheese.

\section{ACKNOWLEDGMENTS}

Authors wish to express gratitude to Pfizer Inc. (New York, NY) for financial support.

\section{REFERENCES}

AOAC. 2005. Official Methods of Analysis. 18th ed. AOAC International, Gaithersburg, MD.
Bierer, D. W. 1990. Bismuth subsalicylate: History, chemistry, and safety. Rev. Infect. Dis. 12(Suppl. 1):S3-S8.

Cotton, F. A., and G. Wilkinson. 1962. Chemistry of nontransitional elements. Pages 385-386 in Advanced Inorganic Chemistry. 3rd ed. John Wiley \& Sons, New York, NY.

Dimosa, A., G. E. Urbach, and A. J. Miller. 1996. Changes in flavour and volatiles of full-fat and reduced-fat Cheddar cheeses during maturation. Int. Dairy J. 6:981-995.

Heslop, R. B., and P. L. Robinson. 1967. Arsenic; antimony; bismuth. Pages 446-467 in Inorganic Chemistry: A Guide to Advanced Study. 3rd ed. Elsevier Publishing Co., New York, NY.

Kosikowski, F. V. 1978. Cheese and Fermented Milk Foods. 2nd ed. F. V. Kosikowski and Associates, Brooktondale, NY.

McNally, V., and J. P. Morgan, inventors. 2001. Antiinfective free intramammary veterinary composition. Bimeda Research and Development Ltd., assignee. U.S. Patent 6,254,881 B1.

Seefeldt, K. E., and B. C. Weimer. 2000. Diversity of sulfur compound production in lactic acid bacteria. J. Dairy Sci. 83:2740-2746.

Woolford, M. W., J. H. Williamson, A. M. Day, and P. J. A. Copeland. 1998. The prophylactic effect of a teat sealer on bovine mastitis during the dry period and the following lactation. N.Z. Vet. J. 46:12-19.

Zhang, W., Z. Yang, X. Huang, S. Zhang, W. Yu, Y. Qian, Y. Jia, G. Zhou, and L. Chen. 2001. Low temperature growth of bismuth sulfide nanorods by a hydrothermal method. Solid State Commun. 119:143-146. 